\title{
Synchronisation of Oestrous in Stall Fed Malnad Gidda Cattle: A Comparative Study
}

A. Murugeppa ${ }^{1 *}$, V. Chandrashekara Murthy ${ }^{2}$, A. Krishnaswamy ${ }^{2}$, G. Sudha ${ }^{2}$, N. Prakash ${ }^{3}$, Vijay Kumar Shettar ${ }^{4}$, N.B. Shridhar ${ }^{5}$ and N.S. Hanumantha Raju ${ }^{1}$

${ }^{1}$ Department of Veterinary Gynaecology and Obstetrics, Veterinary College, Shivamogga, Karnataka, India

${ }^{2}$ Department of Veterinary Gynaecology and Obstetrics, Veterinary College, Bengaluru, Karnataka, India

${ }^{3}$ Veterinary College, Shivamogga, Karnataka, India

${ }^{4}$ Department of Animal Genetics and Breeding, Veterinary College, Gadag, Karnataka, India

${ }^{5}$ Department of Veterinary Pharmacology and Toxicology, Veterinary College, Shivamogga, Karnataka, India

*Corresponding author

\begin{tabular}{|l|}
\hline K e y w o r d s \\
Malnad gidda, \\
Repeat breeder, \\
Estrus, \\
Synchronization, \\
Hormone, GnRH, \\
PGF2 $\alpha$, hCG \\
\hline Article Info \\
\hline $\begin{array}{l}\text { Accepted: } \\
\text { 12 June } 2019 \\
\text { Available Online: } \\
\text { 10 July } 2019\end{array}$ \\
\hline
\end{tabular}

Number of estrus synchronization programmes is available in cattle with hormones combinations of PGF2 $\alpha$, Gonadotrophin Releasing hormone $(\mathrm{GnRH})$, and Leutinizing Hormone (LH). Comparative study of different estrus synchronization protocols in Malnad Gidda cows was done in stall fed Malnad Gidda cattle. The study was conducted in stall fed cattle with repeat breeding. Group I served as control in which the animals were artificially inseminated whereas the group II animals received a treatment of GnRH on day 0, PGF2 $\alpha$ on day 7 followed by administration of another dose of GnRH on day 9 and AI on day 10. The group II animals were administered with first dose of GnRH on day 0, a dose of PGF $2 \alpha$ on day 7 and a dose of hCG on day 9 followed by insemination on day 10. Whereas, the group III animals administered with two doses of PGF2 $\alpha$ on day 0 and day 11 after palpation of active CL. On day $13 \mathrm{GnRH}$ was administered and on day 14, the insemination was done. The conception rate was, in control group, group I, group II and group III, conception rate was of 32.14, 53.33, 64.51and 66.66 per cent respectively. The present study revealed the synchronization of oestrous give the better conception rate.

\section{Introduction}

Synchronization of estrus implies the manipulation of the estrous cycle or induction of estrus to bring a large percentage of a group of females into estrus at a short and predetermined time (Odde, 1990). Synchronization of estrus is one of the 
management process through which the humane errors and management costs could be minimized. It is particularly beneficial in sheep, where timely heat detection is difficult due to exhibitions of less external heat symptoms and also in large cattle herd. Several authors described the experiments that have been conducted since the discovery of ovarian steroids and which lead to the effective control of the length of the bovine estrous cycle and the timing of estrus and ovulation (Hansel and Schechter, 1972; Odde, 1990).

Synchronization of estrus helps in fixing the breeding time within a short predefined period and thereby scheduling the parturition time at the most favorable season, when the newborns can be reared in suitable environment with ample food for enhancing their survivability. Fertility in farm animals may be expected towards higher side as timely breeding of the animals is possible with this technique. Estrus synchronization provides more economic returns by improving the production efficiency in animals (Prusley et al., 1995).

Synchronization can shorten the breeding period to less than five days from 21 days depending on the treatment regimen. Scientific management of cows and calves is possible within the limited resources. Production of uniform calf crop for the future replacement in the farm is important advantage. The current and future direction of estrous synchronization is to focus on combining traditional methods of controlling cycle length with the manipulation of follicular development. The immediate goal of controlling both CL function and follicular development is to design a treatment that will synchronize estrus more precisely and to control the time of ovulation more exactly to allow a single, timed insemination without the need for detection of behavioural estrus (Vinod et al., 2016).
Combination of GnRH with thePGF $2 \alpha$ based synchronization programme has shown a new direction in the estrus synchronization of Malnada Gidda cattle withthe manipulation of follicular development. Stall fed Malnad Gidda cattle do exhibit the repeat problem due to the management problem compared to grazing ones (Ramesha et al., 2013). Knowledge on the hormonal profile and functional structures present in the ovaries at various stages of estrous cycle is important for the selection and successful implementation of the estrus synchronization programme (Prusley et al., 1995).

\section{Materials and Methods}

Stall fed Malnad Gidda cattle for the present investigation was selected in Shivamoga, Chickmagalur and Uttara Kannada districts of Karnataka.

Repeat breeding stall fed Malnad Gidda cows with a minimum of one calving and less than 10 years of age with no palpable genital abnormalities and having normal or nearly normal estrus cycle which fail to conceive even after three subsequent AI with quality Malnad Gidda bull semen in terms good sperm motility and structure were utilized for the study were used in the present study. The animals were apparently healthy in nature with optimum feeding and mineral mixture supplementation.

The animals were fed with green and dry fodder ad libitum throughout the study period. All the animals were maintained under identical management conditions. The management practices were supervised for uniformity during entire period of study. The acclimatization period was four weeks before the start of experiment.

A total of 251 Malnad Gidda cattle with reported repeat breeding were selected after 
thorough gynaecological and clinical examination. Among them, 4 groups of random number of animals were subjected to different hormonal protocol for induction of estrous.

The Control group animals consisted of 28 Malnad Gidda of age group ranging from 3.5 years to 14 years which had calved once, either multiparous or pluriparous with the oestrous cycle length of 21 days were selected. The animals were inseminated with quality Malnad Gidda frozen semen.

\section{The Group I}

Cattle comprised of 32 repeat breeding Malnad Gidda cows. Cows in this group received a dose of $\mathrm{GnRH}$ (10 ug/animali/m, or $2.5 \mathrm{ml}$ of Gynarich $^{\circledR}$, Buserelin Acetate, $4 \mu \mathrm{g} / \mathrm{ml}$ vial, Intas Pharmaceuticals Pvt Ltd, Ahemadabab, India) on day 0 (Day of start of treatment) and $\mathrm{PGF}_{2} \alpha(500 \mu \mathrm{g} /$ animal, $\mathrm{i} / \mathrm{m}$, Pragma ${ }^{\circledR}$, Cloprostenol Sodium, $250 \mu \mathrm{g} / \mathrm{ml}$ vial, $10 \mathrm{ml}$ vial, Intas Pharmaceuticals, Pvt Ltd, Ahemadabab, India) i/m on day 7.

A second dose of GnRH was administered on day 9 and Fixed Time Artificial Insemination (FTAI) was done after $16-20 \mathrm{~h}$ or on day 10.

\section{The group II}

Comprised of 34 repeat breeding Malnad Gidda cows. Cows in this group received a dose of GnRH (10 ug/animali/m, Gynarich ${ }^{\circledR}$, Buserelin Acetate, $4 \mu \mathrm{g} / \mathrm{ml}$ vial, Intas Pharmaceuticals Pvt Ltd, Ahemadabab, India) on day 0 (Day of start of treatment) and $\mathrm{PGF}_{2} \alpha\left(500 \mu \mathrm{g} /\right.$ animal, $\mathrm{i} / \mathrm{m}$, Pragma ${ }^{\circledR}$, Cloprostenol Sodium, $250 \mu \mathrm{g} / \mathrm{ml}$ vial, $10 \mathrm{ml}$ vial, Intas Pharmaceuticals, Pvt Ltd, Ahemadabab, India) i/m on day 7 . On day 9, a dose of hCG was administered (1500 IU, IV, Chorulon $^{\circledR}$, MSD Animal Health Ltd, Pune, India) and insemination was done on day 10.

\section{The group III}

Consisted of 33 Malnad Gidda cattle and the first dose of $\mathrm{PGF}_{2} \alpha$ was administered after palpation of the active CL which is considered as day 0 . The second dose of $\mathrm{PGF}_{2} \alpha$ was administered on day 11 .

On day $13, \mathrm{GnRH}$ was administered and the AI was done on day 14.

\section{Pregnancy diagnosis}

Cows in all the groups were subjected to pregnancy diagnosis by per rectal examination followed by ultra sound examination after 30 days and by rectal examination on 45 days after AI.

\section{Conception rate}

Conception rate was calculated as the percentage $(\%)$ of pregnant animals out of the total inseminated animals.

\section{Statistical analysis}

The data obtained from the present study were subjected to statistical analysis with the aid of computerized statistical software. One-way ANOVA followed by Dunnett's multiple comparisons test $0.05 \%$ level of significance was performed using Graph Pad Prism trial version 6.00 for Windows, Graph Pad Software, La Jolla California USA, www.graphpad.com. Mean values and standard error of mean were calculated and all the values were expressed as Mean \pm SE (Graph Pad Prism 6.00, Trial Version, 2007).

\section{Results and Discussion}

The repeat breeding Malnad Gidda animals synchronized with the oestrous with two doses of GnRH and PGF2 $\alpha$ and LH. Following is the result. 
The conception rate in control stall fed Malnad Gidda cows was significantly low $(\mathrm{P}<0.05)$ compared to all the treatment groups. The animals responded to the treatment in group I, II and III were 93.75, (30 out of 32), 91.11, (31 out of 34) and 81.81 per cent (27 out of 33) respectively. Most of the animals in all the groups responded well to the treatment protocols.

The conception rate achieved in different group of Malnad Gidda cattle is presented in Table 1 and Figure 1. The conception rate was, in control group, group I, group II and group III, conception rate was of 32.14, 53.33, 64.51and 66.66 per cent respectively.

In the present study the conception in stall fed Malnad Gidda cattle was 32.14 percent which was low compared to the treatment groups. Cattle breed has significant effect over conception rate. Highest (49.17\%) conception rate (CR) was observed in Dangi breed of cows and lowest (41.36\%) in Holstein Friesian there was difference in conception rate among the different breeds of cows. Rao et al., (1992) observed higher conception rate of indigenous cows than other genotypic groups. Besides this, it was also reported that conception rate was significantly $(\mathrm{P}<0.01)$ higher in Sarda cows $(95 \%)$ than Charolasis $\times$ Sarda cows
$(57 \%)$. In practices, it is difficult to find out the effect of cattle breed on their fertility. Environmental and management conditions those might have more influence on fertility (Vinod et al., 2016).

Malnad Gidda is the free roaming cattle in the forests of Western Ghats. Usually there will be natural breeding at that time and there will be a good fertility rate. Recently, due to stall feeding and limited exercise, there is increasing trend of repeat breeding in these animals. The animals need to be inseminated artificially. The repeat breeding is a universal problem which is multifactorial in nature. Many efforts are there to set the matter right and synchronization of oestrous is one among them. There are many protocols for the synchronization of oestrous in repeat breeding cattle. In the present study, three such protocols are studied and compared. Such type of study is conducted by many scientists earlier also (Pusley et al., 1995; Vinod et al., 2016).

There was low conception rate in stall fed Malnad Gidda. This might be attributed to lack of exercise, increasing accumulation of adipose tissue in the body, deficiency of essential trace minerals, hormonal imbalance, over or under nutrition (Ramesha et al., 2013).

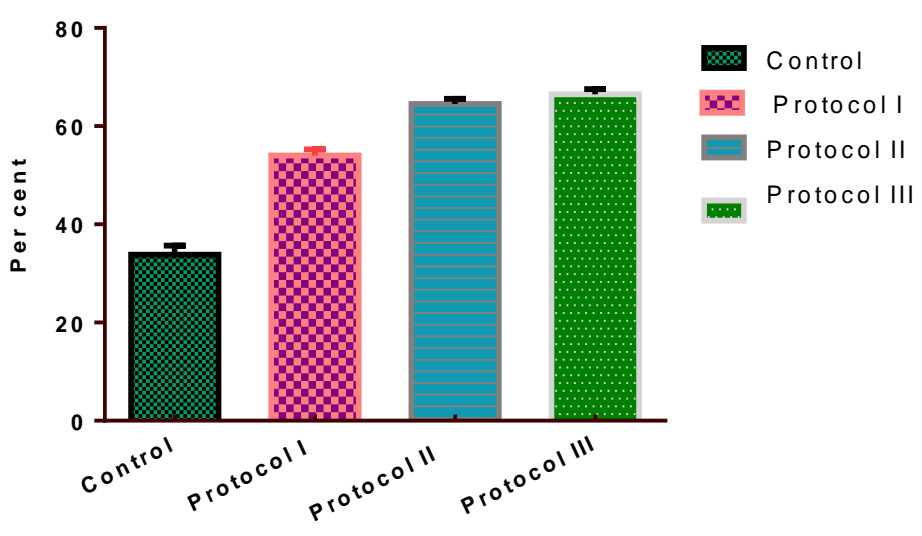

Figure 1: Conception rate in different groups of Malnad Gidda cattle 
Table.1 Conception rate in synchronization protocols of Malnad Gidda cows

\begin{tabular}{|c|c|c|c|c|}
\hline $\begin{array}{l}\text { Experimental } \\
\text { group }\end{array}$ & $\begin{array}{c}\text { Protocol } \\
\text { details }\end{array}$ & $\begin{array}{l}\text { No. of cows } \\
\text { responded } \\
\text { and } \\
\text { inseminated }\end{array}$ & $\begin{array}{l}\text { No. of cows } \\
\text { conceived }\end{array}$ & $\begin{array}{c}\text { Per cent } \\
\text { conception }\end{array}$ \\
\hline Control $(n=28)$ & - & 28 & 9 & $32.14^{\mathrm{a}}$ \\
\hline Group-I $(n=32)$ & $\begin{array}{l}\text { GnRH (day } \\
\text { 0)-PGF2 } \alpha \\
\text { (day } \\
\text { GnRH (day } \\
\text { 9)-AI (day } 10)\end{array}$ & 30 & 16 & $53.33^{\mathrm{b}}$ \\
\hline Group-II (n=34) & $\begin{array}{l}\text { GnRH (day } \\
\text { 0)-PGF2 } \alpha \\
\text { (day } 7)- \text { hCG } \\
\text { (day 9)-AI } \\
\text { (day 10) }\end{array}$ & 31 & 20 & $64.51^{b}$ \\
\hline Group-III (n=33) & $\begin{array}{l}\text { PGF2 } \alpha \text { (day } \\
\text { 0)- PGF2 } \alpha \\
\text { (day 11)- } \\
\text { GnRH (day } \\
\text { 13)-AI(day14) }\end{array}$ & 27 & 18 & $66.66^{b}$ \\
\hline
\end{tabular}

The values with different superscripts do vary significantly $(\mathrm{P}>0.05)$

In the present study, the first protocol in group I consisted of administration of $\mathrm{GnRH}$ on day 0, PGF $2 \alpha$ on day 7 followed by administration of another dose of GnRH on day 9 and AI on day 10. In the present study, the percent conception is 53.33 percent which is significantly higher $(\mathrm{P}<0.05)$ than that of the control group which is in accordance with the finding of the earlier authors (Ashvinkumar Chaudhari et al., 2018; Vinod et al., 2016). Similar protocol was also used by Pursley et al., (1995) in cattle to synchronize the oestrous who also got 55.00 percent of conception rate in cattle. The first dose of GnRH will induce the follicular development with subsequent release of oestrogen. Hence the animal expresses the oestrous. On day 7, a dose of PGF $2 \alpha$ will cause leutolysis and makes the animal to come to oestrous. The increased conception in the treatment compared to the control group might be attributed primarily due to luteolytic action of PGF $2 \alpha$ and GnRH has the property of inducing follicular growth and ovulation. Many workers have confirmed the efficacy of the combination of these hormones in ovsynch protocols. In the present also, the increased conception rate in group I might be attributed to the same mechanism (Pursley et al., 1995; Bartolome et al., 2004).

The group II animals administered with first dose of GnRH on day 0, a dose of PGF $2 \alpha$ on day 7 and a dose of hCG on day 9 followed by insemination on day 10 . This protocol revealed the conception rate of 64.51 per cent. This is also significantly higher compared to the control group exhibiting the percent conception of 32.14. In this group also, the of GnRH might have released the FSH and LH by which the ovaries become functional and due to release of oestrogen, the animal expresses the oestrous signs. After ovulation, under the influence of LH, the CL might have 
developed which was knocked down by the administration of PGF $2 \alpha$. This finding is in accordance with the finding of Pursley et al., (1995) who also reported the similar findings. Further, the administration on day 9 might have influenced the ovulation in time and might have increased the conception rate. This finding is in according with Geary et al., (2001) who reported that the use of GnRH and hCG will improve the conception rate with PGF2 $\alpha$.

The group III animals administered with two doses of PGF $2 \alpha$ on day 0 and day 11 after palpation of active CL. On day $13 \mathrm{GnRH}$ was administered and on day 14 , the insemination was done. The conception rate in the protocol was 66.66 which were significantly higher than the control group. This finding is accordance with the finding of Vasconcelos et al., (2001) who reported that that the corpus luteum of cows that ovulate after the first PGF $2 \alpha$ are more likely to undergo luteolysis in response to second dose of PGF $2 \alpha$ and have a greater synchronization rate compared with cows that do not respond to first GnRH. Moreover, if cows ovulate after first GnRH, they are more likely to have a functional dominant follicle capable of ovulation. Further, administration of GnRH will increase the conception rate due to the timely release of ova (Pursley et al., 1995).

In all three protocols, the non-responsiveness of the animals to the synchronization of oestrous in group I, 2 out of 32, in group II 3 out of 34 and in group III 6 out of 33. The non-responsiveness to the hormonal treatment might be due to the ovarian dysfunction, hormonal imbalance, nutritional under feeding and many more factors as indicated by Schilling et al., (1982).

In conclusion, in the present study, the conception rate was increased in all the three protocols compared to the control untreated group indicating the suitability of the synchronization of oestrous in stall fed Malnad Gidda animals which indicated the usefulness of these protocols to increase the fertility rate and thus to prevent the economic loss to the farmer.

The authors are thankful to Karnataka Veterinary Animal and Fisheries Sciences University, Bidar for providing the facilities to conduct the research work. The authors are also thankful to Dr. K.P. Ramesha, Head, NDRI, Bengaluru for his timely help.

\section{References}

Ashvinkumar Chaudhari, Nilufar Haque, Natvarbhai Jamnesha, Nikita Bhalakiya, Gaurangkumar Patel, Mahesh Madhavatar, Dhavalkumar Patel and Pankaj Patel, 2018: Synchronization of Estrus: A reproductive management tool in veterinary practice, Int.J.Curr.Microbiol.App.Sci., 7: 15111519.

Bartolome, J.A., Archbald, L.F. and Morresey, P., 2004. Comparison of synchronization of cysts in the dairy cow, Theriogenol., 53: 815-825.

Geary, T.W., Salverson, R.R. and Whittier, J.C. 2001. Synchronization of ovulation using GnRH or hCG with the co-synch protocol in suckled beef cows. J.Anim. Sci., 79: 2536-2541.

GraphPad Prism, 2007. GraphPad Prism trial version 6.00 for Windows, Graph Pad Software, La Jolla California USA, www.graphpad.com.

Hansel, W. and R. J. Schechter, 1972: Biotechnical procedures concerning the control of the estrous cycle in domestic animals. VII ${ }^{\text {th }}$ Int. Cong. Anim. Reprod. Artif. Insem. Munich, 1:78-96.

Odde, K.G., 1990. A review of synchronization of estrus in postpartum cattle. J. Anim. Sci., 68(3): 817-830. 
Pursley, J.R., Mee. M.O. and Wiltbank. M.C., 1995. Synchronization of ovulation in dairy cows using $\mathrm{PGF}_{2}$ and $\mathrm{GnRH}$. Theriogenol., 44: 915-923.

Ramesha, K. P., Jeyakumar, S., Kataktalware, M. A., Das, D. N. and Nagaraj, K. M., 2013. Geographical distribution, present status and characteristics of Malnad Gidda cattle - An unique dwarf cattle of Western Ghats in Karnataka, Indian Biodiversity Congress, Biodiversity documentation and taxonomy, $p p$ : 429434.

Rao, A.V.M., M.S. Naidu and Y.N. Murthy, 1992. Effects of breed type of season on conception rates in cows. World. Rev. Anim. Prod., 27: 23-25.

Schilling, E. Jochle, W. and Smidt, D. 1982:
Estrous cycle synchronization in dairy heifers with the prostaglandin analog alfaprostol (II). Therigenol, 18(4): 413422.

Vasconcelos, J. L. M., Silcox, R. W., Rosa, G. J. M., Pursley, J. R. and Wiltbank, M. C., 1999. Synchronization rate, size of the ovulatory follicle, and pregnancy rate after synchronization of ovulation beginning on different days of the estrous cycle in lactating dairy cows. Theriogenol., 52(6): 1067-1078.

Vinod, V. P., Kaustubh B., Yuvraj, G., Hitesh, R.A. and Jayant, R.K., 2016. Factors influencing conception rate of local and crossbred cows. IOSR J. Agri. Vet. Sci.10:51-54.

\section{How to cite this article:}

Murugeppa, A., V. Chandrashekara Murthy, A. Krishnaswamy, G. Sudha, N. Prakash, Vijay Kumar Shettar, N.B. Shridhar and Hanumantha Raju, N.S. 2019. Synchronisation of Oestrous in Stall Fed Malnad Gidda Cattle: A Comparative Study. Int.J.Curr.Microbiol.App.Sci. 8(07): 1351-1357. doi: https://doi.org/10.20546/ijcmas.2019.807.161 